\title{
Histerectomia possíveis alterações sexuais e influências do nível sócio econômico
}

Seqüelas psicológicas da histerectomia são discutidas, em referência aos resultados de pesquisa com mulheres de diferentes camadas sociais e econômicas, com idade entre 25 e 50 anos, anteriormente submetidas à excisão do útero.

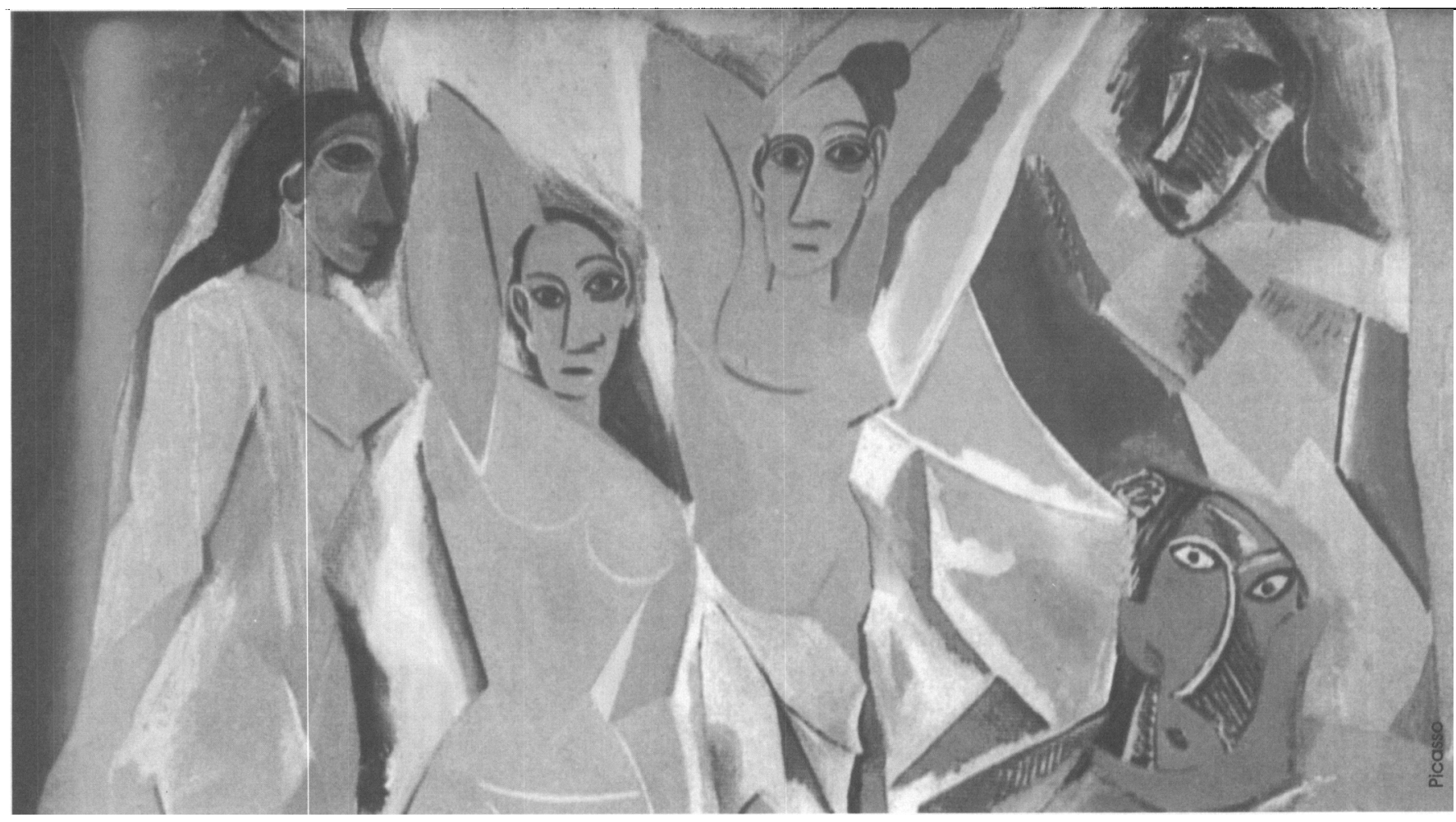

"A

Histerectomia é um tipo de operação que consiste na excisão do útero, realizada sempre através da parede abdominal ou pela vagina" (Saunders, 1976, p.756). Atualmente a Histerectomia constitui uma das cirurgias femininas mais freqüentes no mundo ocidental, o que mostra a importância do estudo de suas seqüelas psicológicas.

Apesar de, na literatura médica, nada indicar que a Histerectomia leve a alterações sexuais, a associação psicológica entre a procriação e a sexualidade pode afetar as mulheres submetidas a essa cirurgia nos seguintes aspectos: auto-conceito, sintomas depressivos, relacionamento sexual e conjugal, sintomas psicossomáticos etc. Vários autores têm discutido a incidência dessas problemáticas, o que resultou em controvérsias. Enquanto alguns pesquisadores constataram alta incidência de depressão após a Histerectomia (Barker, 1968; Baker \& Quinkert, 1984; Drellich \& Bieber, 1958;.

Maria da Conceição Loureiro

Psicólogo Especializada em Filosofia Hollender, 1960; Malbe \& cols. 1988; Kroger, 1963; Melody, 1962) outros (Bragg, 1965; Meikle Brody \& Pysh, 1979; não observaram seqüelas psicossociais e emocionais decorrentes da Histerectomia ou as vincularam a um histórico anterior de depressão (Gath, 1980; Martin, Roberts, Clayton \& Wetzel,1980; Michaud \& Engelsmann, 1988; Roeske, 1979). 
Os problemas específicos da esfera sexual foram observados por Michaud \& Engelsmann (1988), Richards (1974), Dennerstein \& Burrouws (1977), Alves (1989), Guzman \& Ortega (1984) e Drellich \& Bieber (1958). Para esses autores, a Histerectomia é sentida pela mulher como um golpe no seu território de prazer, sendo constatado: decréscimo na freqüência do coito, deterioração no ajustamento e no relacionamento sexual, diminuição do desejo sexual e menor capacidade de resposta sexual.

A esse respeito, Leiblum (1990) enfatiza a importância de trabalhar a expectativa préoperatória com a mulher que vai ser histerectomizada, o que contribuiria para atenuar as dificuldades sexuais. Mais recentemente, Ferroni (1994) constatou aumento na satisfação com a atividade sexual em mulheres histerectomizadas.

Os medos na área de mudanças físicas sentimentos de mutilação, de ameaça ao autoconceito e à imagem corporal foram evidenciados ainda por Michaud \& Engelsmann (1988)e, no Brasil, por Teitelroit (1980), que os denomina perda e revivência da fantasia de castração. Drellich \& Bieber (1958) relataram que, apesar de a menstruação ser considerada um período desagradável, muitas mulheres a percebem como uma função útil; nesse sentido, após a Histerectomia, são assinaladas a diminuição do desejo sexual, menor capacidade de resposta sexual e preocupação pela possível infidelidade do marido.

Cabe observar que em nenhum dos estudos relatados foi considerada a variável nível sócioeconômico, sendo esse aspecto abordado tangencialmente por Michaud (1989); este autor sugere que fatores culturais como nível educacional, sociedade do tipo matriarcado ou patriarcado e outros podem contribuir para a reação à Histerectomia em mulheres de diferentes "backgrounds" étnicos.

Assim, as controvérsias nas formulações teóricas e empíricas a respeito da influência da
Histerectomia na sexualidade feminina nos levaram a comparar os efeitos dessa cirurgia em mulheres de dois níveis sócio-econômicos: classe operária e classe média-alta. Presumimos que, devido ao fato de o esclarecimento prévio à cirurgia ser mais precário na classe operária, as alterações sexuais seriam mais freqüentes e mais acentuadas nas mulheres dessa classe social.

\section{METODOLOGIA Tipologia da Pesquisa}

Cabe ressaltar que trata-se de estudo retrospectivo, no qual as mulheres entrevistadas relataram suas percepções e sentimentos conforme foram lembrados. Assim sendo, as evidências não são conclusivas na medida em que os relatos podem estar impregnados de distorções, em grande parte devido ao intervalo de tempo decorrido.

Um estudo prospectivo com maior controle das variáveis estranhas e ampliação da amostra seria desejável. Com um maior número de mulheres que fossem entrevistadas antes e após a cirurgia os resultados talvez fossem mais confiáveis. No entanto, tais medidas poderiam inviabilizar o estudo devido, primeiramente, a grande perda de sujeitos (de 130 iniciais terminamos com apenas 23 de cada grupo). Em segundo lugar, temos a dificuldade de se fazer uma avaliação da sexualidade da mulher antes da cirurgia, devido a situação estressante em que ela se encontra.

Como não temos uma informação mais confiável sobre o bem estar psicológico e sexual antes da cirurgia, as conclusões acerca do efeito da Histerectomia na sexualidade feminina devem ser encarados com certa cautela.

\section{Amostra}

As mulheres de classe operária foram selecionadas mediante o apoio e a autorização da chefia da 28a Enfermaria da Santa Casa da Misericórdia, o que possibilitou a seleção de 130 fichas de pacientes, que atendiam aos seguintes critérios: (1) idade entre 25 e 50 anos; (2) nível sócio-econômico baixo (renda familiar 
máxima de três salários mínimos); (3) nível de instrução máximo $1^{\circ}$ grau e (4) realização da Histerectomia há pelo menos um ano. Foi encaminhada a essas pacientes uma carta solicitando o seu comparecimento para uma revisão da cirurgia. Atenderam à solicitação 23 mulheres, que exerciam profissões próprias da classe, tais como: doméstica, costureira, faxineira ou atividades do lar.

A amostra da classe média-alta, também composta de 23 mulheres, foi selecionada por indicação do ginecologista e obstetra da Clínica São Vicente, sendo equivalente à classe operária nos critérios 1 e 4; essas mulheres tinham renda familiar entre 100 e 200 salários mínimos e, em sua maioria, curso superior e profissões correspondentes ao seu nível de instrução.

\section{Instrumento}

Foi formulado um questionário fechado, adaptado do questionário utilizado por Teitelroit em seu estudo "Histerectomia e Revivência da Fantasia de Castração". Esse questionário focalizou os seguintes dados:

\section{(1)Sentimentos despertados face à menarca;}

(2) Sentimentos provocados pela primeira relação sexual;

(3) Sentimentos relativos à Histerectomia antes e após a sua realização;

(4)Interesse pelo relacionamento sexual antes e após a Histerectomia.

(5) Grau de prazer com a relação sexual antese após a cirurgia.

A realização de um pré-teste, visando avaliar a adequação da linguagem utilizada, evidenciou a necessidade de aplicar o questionário sob a forma de uma entrevista padronizada, possibilitando uma maior clarificação das respostas aos questionários, especialmente na classe operária. Foram também anotadas as observações e explicações adicionais dos sujeitos, que foram utilizadas para a análise qualitativa dos dados.

\section{Procedimento}

O questionário-entrevista foi aplicado individualmente em uma única sessão, pela segunda pesquisadora. As mulheres da classe operária dirigiam-se a uma sala, reservada com essa finalidade, na Santa Casa da Misericórdia.
A pesquisadora explicou o objetivo do estudo, solicitou a sua colaboração e, após a aplicação do instrumento, tirou possíveis dúvidas sobre a Histerectomia e suas seqüelas. As mulheres da classe média-alta que, contactadas por telefone, se dispuseram a participar do estudo, foram entrevistadas em suas residências.

\section{DEFINIÇÃO DOS TERMOS}

Classe social - cada um dos grupos de pessoas que têm a mesma função, os mesmos interesses, a mesma condição numa sociedade, ou a mesma situação no sistema de produção.

Classes Sociais no Brasil (Urbana) - de acordo com PEA (População Economicamente Ativa):

Classe Operária - Todos aqueles que produzem valor, incluindo aqueles de salários muito baixos (construção civil).

Classe Média-Alta - Autônomos de renda alta; profissionais liberais de renda mais alta.

\section{ANÁLISE DOS RESULTADOS}

Os dados quantitativos obtidos pela aplicação dos questionários foram submetidos à análise descritiva e inferencial. Foram elaboradas tabelas simples e cruzadas, com as respectivas freqüências absolutas e percentuais. Foi aplicado o teste $z$ para verificar a significância de diferenças entre duas proporções em relação às seguintes comparações:

(1) Sentimentos despertados pela menarca na classe operária e classe média-alta $(z=3$, $18 p<0,01$ ), evidenciando uma percepção mais negativa por parte das mulheres da classe operária do que as da classe média-alta;

(2) Sentimentos despertados pela primeira relação sexual, predominantemente negativos em ambas as classes $(z<1$ n.s.);

(3) Sentimentos associados à Histerectomia antes da realização da cirurgia equivalentes para as duas classes $(z<1 \quad$ n.s.), sendo enfatizadas expectativas relativas à saúde, 
seja em seus aspectos gerais, seja quanto à melhoria dos sintomas que levaram à cirurgia; e

(4) Após a Histerectomia, as duas amostras passaram a diferir significativamente, acentuando-se nas mulheres da classe média-alta em relação à classe operária $(\mathrm{z}=4,2 \mathrm{~s} .1 \%)$ a expectativa de que a retirada do útero levaria a um prejuizo irreparável da feminilidade.

Foi também aplicada a Prova de Mc Nemar para significância de mudanças, a fim de verificar alterações no interesse pelo relacionamento sexual e no grau de prazer usufruído antes e após a Histerectomia. Quanto ao interesse pelo relacionamento sexual, este aumentou significativamente $(2=4,0 \mathrm{p}<$ 0,025 ) nas mulheres da classe operária mas não nas da classe média-alta $(2<1$ n.s). Observamos também que nem as mulheres da classe operária ( $2<1$ n.s) nem as da classe média-alta ( $2=1,8$ n.s.) tiveram o seu grau de prazer influenciado significativamente pela Histerectomia.

Além dos dados quantitativos, foram obtidas informações adicionais de caráter qualitativo. Foi assim constatada a alta incidência (seis em 23 mulheres) de mulheres da classe média-alta que começaram a fazer psicoterapia em função da Histerectomia. O número de separações atribuídas pelas mulheres da classe média-alta à cirurgia também foi expressiva (sete). Em ambas as classes os parceiros evidenciaram preconceito em relação à atividade sexual da mulher histerectomizada, levando algumas mulheres a recorrer a relações extra-conjugais em que omitia a realização da cirurgia dos novos parceiros sexuais.

\section{DISCUSSÃO}

O objetivo da presente pesquisa foi estudar, de forma retrospectiva, as alterações da sexualidade em mulheres submetidas à Histerectomia, em função da classe social. Não foi confirmada a hipótese de que as mulheres de nível sócioeconômico baixo (classe operária) teriam seu interesse e sua satisfação com a relação sexual prejudicados, em contraste com as mulheres de nível sócio econômico médio-alto; esta hipótese corresponderia a discrepância entre os dois grupos quanto ao nível de informação sobre a Histerectomia. Ao contrário, a comparação entre os dois grupos mostrou que nas mulheres da classe operária, tanto a motivação para o ato sexual como o grau de prazer com ele usufruído se intensificaram (conforme relato delas) do pré para o pós operatório. Em contrapartida, as mulheres da classe média-alta relataram uma maior variação quanto a alteração em seu grau de prazer após a Histerectomia, não havendo efeito da cirurgia na motivação para o relacionamento sexual. Ademais, o sentimento de perda da feminilidade associado à retirada do útero acentuou-se nas mulheres da classe média-alta, ocorrendo o oposto com as mulheres da classe operária.

A respeito desses achados, Muraro (1983) elaborou duas contribuições teóricas baseadas em seus próprios estudos de campo. Ao comparar homens e mulheres das classes operária e burguesa, quanto à influência do

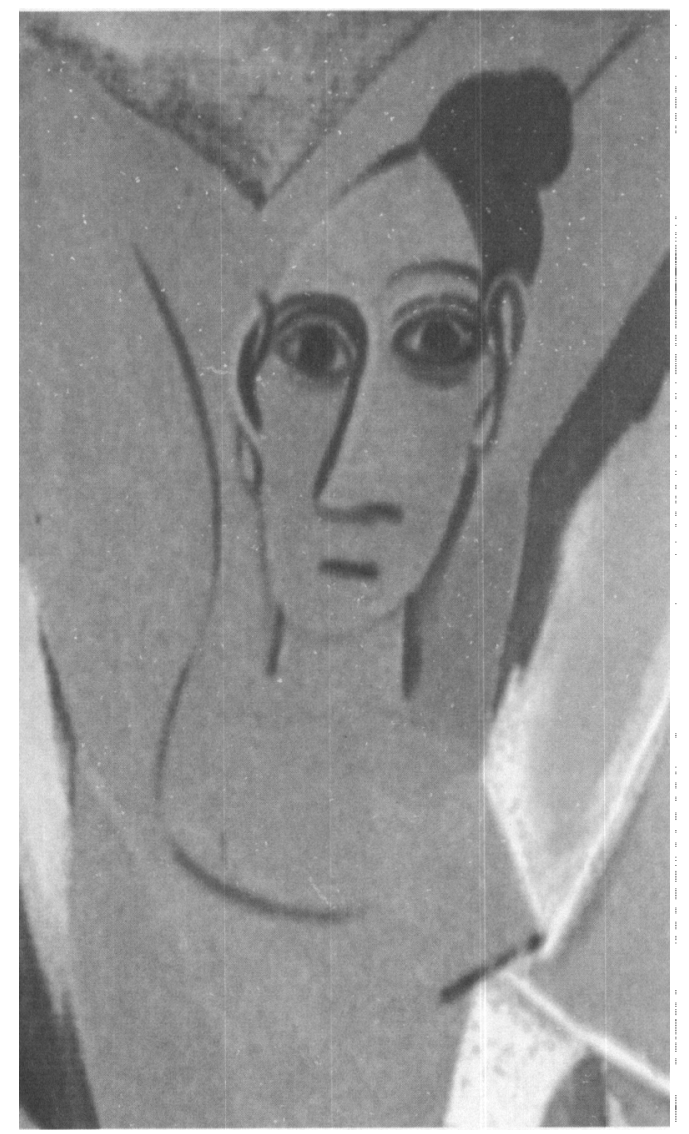

Ademais, o sentimento de perda da feminilidade associado ò retirada do útero acentuou-se nas mulheres da classe média-alta, ocorrendo o oposto com as mulheres da classe operária. 
É evidente que, nesse contexto, 0 binômio saúdebeleza vinculado ao corpo levaria a mulher da classe média-alta, após a Histerectomia, a se sentir menos feminina, o que comprometeria o seu desempenho sexual. nível sócio-econômico em diversos aspectos, observou que os valores e atitudes das mulheres da classe operária permitiram classificá-las como detentoras de "um corpo-para-aprodução". Este corpo estaria voltado para o trabalho manual e distante do mercado de consumo de bens destinados ao embelezamento e à manutenção da saúde. Nesse contexto, a simples eliminação dos sintomas desagradáveis que levaram à Histerectomia propiciaria, a essas mulheres, a recuperação do corpo para a obtenção de mais prazer sexual.

Em contraste, ainda segundo Muraro, as mulheres da classe burguesa seriam detentoras do "corpo-para-o-consumo", referindo-se aos cuidados dispensados à saúde e à estética. É evidente que, nesse contexto, o binômio saúdebeleza vinculado ao corpo levaria a mulher da classe média-alta, após a Histerectomia, a se sentir menos feminina, o que comprometeria o seu desempenho sexual.

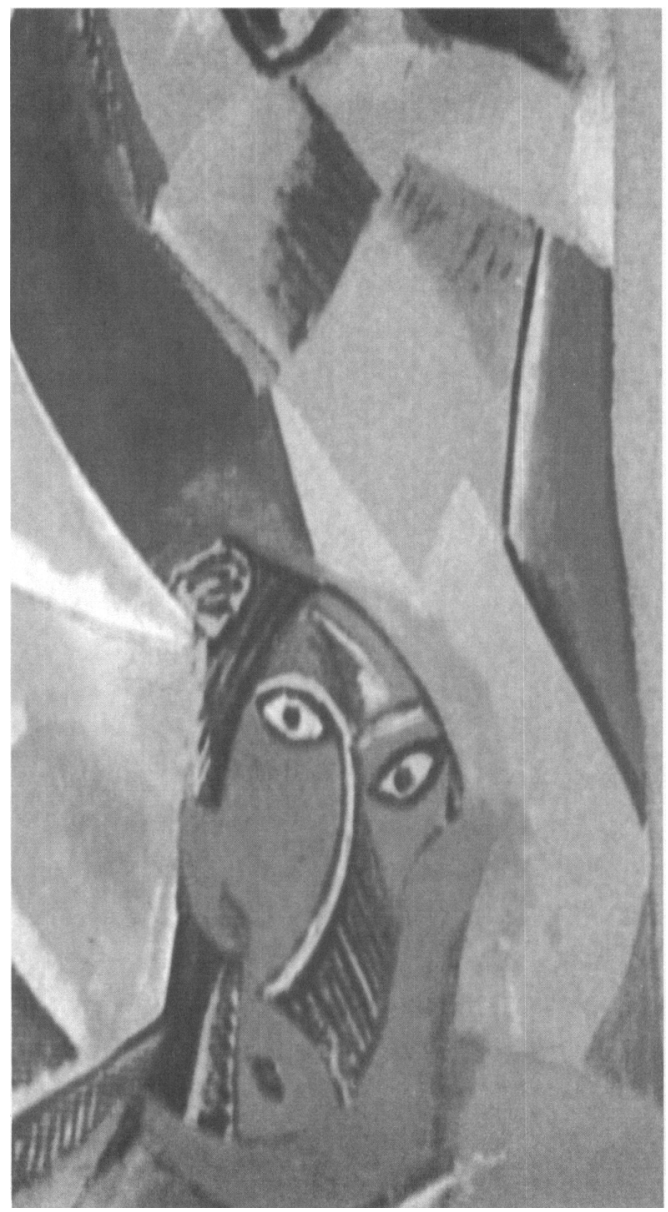

A segunda contribuição de Muraro para elucidar os resultados encontrados em nossa amostra, de mulheres histerectomizadas, foram os dados empíricos obtidos por essa autora quanto à atitude de seus entrevistados em relação à menopausa. Tais dados são interessantes, na medida em que a menopausa e a Histerectomia se equivaleriam na associação entre a sexualidade e a procriação. A autora verificou que a mulher burguesa, na menopausa, abandona a vaidade e a sexualidade. Ela observou que "grande parte $(50 \%)$ das mulheres entrevistadas se retira da vida sexual por ocasião da menopausa" (p.96) e que os homens também rejeitam (70\%) a mulher quando ela entra na menopausa.

A valorização diferencial da mulher da classe operária e burguesa quanto à ênfase dada à feminilidade, beleza, juventude, capacidade para o trabalho físico etc. está estreitamente ligada à desvalorização sexual da mulher após a menopausa, que é menos intensa na mulher operária do que na mulher burguesa. Assim, apenas $16,7 \%$ das mulheres e $14,7 \%$ dos homens da classe operária, entrevistados por Muraro, concordam que na menopausa acaba o prazer sexual.

Estes dados dão respaldo teórico, ainda que indiretamente, à intensificação do prazer sexual das mulheres da classe operária por nós entrevistadas. Quanto à atitude dos homens face à Histerectomia, os dados por nós observados foram equivalentes aos obtidos por Muraro, ainda que em menor proporção, em relação à menopausa. Os homens da classe média-alta evidenciaram alto grau de preconceito $(30,4 \%)$ em comparação com os homens da classe operária $(8,7 \%)$, frente à Histerectomia. $\mathrm{Na}$ classe média alta destacou-se um alto número de separações (sete em 23), atribuídas pelas mulheres à rejeição sexual por seus parceiros, após a Histerectomia. A atitude preconceituosa por parte dos parceiros levou algumas mulheres a terem amantes, dos quais escondem que fizeram Histerectomia.

Boltanski (1984) também forneceu subsídios teóricos e empíricos esclarecedores para nossos 
achados ao relacionar, em seu livro As Classes Sociais e o Corpo, as práticas de saúde à estrutura de classes. Segundo esse autor, na medida em que se passa das classes inferiores às superiores na escala social, diminui a valorização da força física ("corpo-para-a-produção" de Muraro) em favor do enaltecimento da beleza e da forma física ("corpo-para-oconsumo" de Muraro), estabelecendo-se uma relação reflexiva com o corpo. Nas mulheres da classe operária que foram objeto de nosso estudo, o esforço físico necessário às suas atividades amorteceria a discriminação apurada das sensações corporais e uma relação mais consciente com o corpo. Logo, a eliminação dos sintomas após a Histerectomia permitiria, a essas mulheres, retomar de forma usual sua sexualidade.

As mulheres da classe média-alta, com atividades mais intelectuais, estabeleceriam uma relação reflexiva com seu corpo o que, aliado aos padrões vigentes de beleza e saúde, as impediria de melhorar seu desempenho sexual em função da Histerectomia. Essa relação reflexiva com o corpo foi expressa pela alta incidência (seis em 23 mulheres) de mulheres que, após a Histerectomia, começaram a fazer psicoterapia, numa tentativa de solução de problemas psicológicos associados à cirurgia.

Parece, enfim, que para algumas mulheres da classe média-alta, um corpo sem útero é sinônimo de corpo sem sexualidade; a associação procriação/sexualidade parece fazer parte do imaginário social e da grande gama de preconceitos de cunho social.

\section{CONCLUSĀO E SUGESTÕES}

Os resultados da pesquisa parecem evidenciar que o nível sócio-econômico é um fator determinante na forma como a Histerectomia é elaborada psicologicamente pela mulher. O estudo das variáveis envolvidas nos padrões sexuais de mulheres histerectomizadas da classe operária e da classe médiaalta é sugestivo de que as mulheres da classe operária vivenciam a excisão do útero de forma pouco traumática, em comparação com as mulheres da classe média-alta.

Ficou evidente que um melhor esclarecimento pré-operatório não é suficiente para que a mulher consiga, assim como seu companheiro, dissociar a capacidade reprodutora do desempenho sexual e da feminilidade propriamente dita. Tais dados são indicativos de que justamente o aumento da atenção dispensada ao corpo e a reflexão sobre as sensações corporais, peculiares à classe média-alta, levariam a um vínculo mais acentuado entre a reprodução e a sexualidade; esta associação levaria a Histerectomia a comprometer o desempenho sexual das mulheres desse nível sócio-econômico. Já para as mulheres da classe operária, o corpo tem um sentido mais prático-objetivo, menos pensado; a eliminação dos sintomas que levaram à necessidade da cirurgia seria suficiente para que a atividades sexual fosse retomada da forma usual e até melhorada.

Cabe ressaltar que, conforme já destacamos, trata-se de estudo retrospectivo e, portanto, as evidências não são conclusivas como quando se utiliza uma estratégia prospectiva; numa pesquisa prospectiva as mulheres seriam acompanhadas antes e após a cirurgia, ao invés de relatarem suas percepções e sentimentos conforme são lembrados. Estudos prospectivos com maior controle das variáveis estranhas elucidariam de forma mais apropriada a nossa questão, qual seja, a influência da Histerectomia na sexualidade feminina.

Maria da Conceiçăo Loureiro 
Referências bibliográficas
Alves, R.C.A. (1989). Sexualidade de mulheres submetidas à histerectomia. Sexus, 1.

Baker, M.A. e Quinkert, K. (1984). Women's reactive to reprodutive problems. Psychological Reports, $53(1)$.

Barker, M.G. (1968). Psychiatric illness after hysterectomy. British Medical. Journal, 2.

Bragg, R.L. (1965). Risk of admission to mental hospital following hysterectomy or cholecystectomy. American Journal of Public Health, 5 .

Boltanski, L. (1984). As classes sociais e o corpo. Rio de Janeiro: Graal.

Dennerstein, M. e Ryan, M. (1982). Psychosocial and emotional sequelae of hysterectomy. journal of Psychosomatic Obstetric and Gynaecology, 1-2.

e Burrows, G.D. (1977). Sexual response following hysterectomy and osphorectomy. Journal of Obstetric and Gynaecology, 49 .

Drellich, M.G. e Bieber, I. (1958). The psychological importance of the uterus and its functions. Journal of Nervous and Mental Disorders, 126.

Gath, D.H. (1980). Psychiatric aspects of hysterectomy. Em L. ClaytoneS. Wing (Orgs.), The social consequences of psychiatric illness, 33-57, New York: Brunner Mazel.

Guzman, A. e Ortega, R.M. (1984). Estudio psiquiatrico pre y post-operatorio en mujeres histerectomizadas: comunicación preliminar. Revista de Obstetricia \& Cinecologia de Venezuela, XLIV(3).

Hollender, M.H. (1960). A study of patients admitted to a psychiatric hospital after pelvic operations. American Journal of Obstetrics and Gynaecology, 79
Malbe, H.W. et al. (1988). Aspectos psicológicos da histerectomia: temores, reações psicológicas pré-operatórias e influência do lar atual. Revista Brasileira de Ginecologia e Obstetrícia. 16(4).

Martin, G., Roberts, H., Clayton, M. e Wetzel, P. (1980). Psychiatric status after hysterectomy: a one year prospective study. Journal of American Medical Assessment., 244.

Meikle, S., Brody, H. e Pysh, F. (1979). An investigation into the psychological effects of hysterectomy. Journal of Nervous and Mental Disorders, 164.

Melody, G.F. (1962). Depressive reactions following hysterectomy. American Journal of Obstetrics and Gynaecology, 83.

Michaud, M.L. e Engelsmann, F. (1988). Psychological profile of depressed women undergoing hysterectomy. Journal of Psycological Obstetrics and Gynaecology, 8.

Muraro, R.M. (1983). Sexualidade da mulher brasileira. Petrópolis: Vozes.

Raglianti, P. (1983). Isterectomia e depressione: indagine clinica. Bolletino di Psicologia Applicata, 155-156(2).

Richards, D.M. (1974). A post-hysterectomy syndrome. Lancet., 11.

Roeske, N.C. (1979). Hysterectomy and the quality of woman's life. (Editorial) Archives of International Medicine, 139.

Saunders, W.B. (1976). Dorlland's Illustrated Medical Dictionary. Philadelphia: Saunders Company.

Teitelroit, B. (1980). Histerectomia e revivência da fantasia de castração: urna exploraçāo através do Rorschach. Psico, 1(2). 


\section{QUESTIONÁRIO}

\section{IDENTIFICAÇÃO}

Nome:

Idade:

Estado Civil:

Profissão:

Escolaridade:.

HISTERECTOMIA INDICADA POR:

( Mioma

( ) Câncer de colo uterino

( ) Hemorragia

(Outros

MENARCA: aos anos

Sentimentos na Menarca

( )Ansiedade

( )Sentimento de doença

( )Satisfação

( ) Medo

( ) Irritabilidade

( )Sintomas Físicos

( )Outros

\section{RELAÇÕES SEXUAIS}

Primeira relação sexual aes anos

Sentimentos na primeira relação

sexual:

( ) Medo

( ) Ansiedade

( ) Dor

( ) Sem reação

( ) Culpa

( ) Satisfação

( ) Dificuldade

( ) Prazer

( ) Sem medo

( ) Outros

O QUE PENSOU SOBRE A CIRURGIA Sentimentos antes da cirurgia

( ) Medo de morrer por causa da anestesia

( ) Via a cirurgia como necessária para a preservação da saúde

( ) Via a cirurgia como uma forma de se livrar de um incômodo

( ) Via a cirurgia como uma perda irreparável

( )Outros.
6. O QUE PENSA HOJE SOBRE A CIRURGIA

( )Foi melhor para sua saúde

( )Foi melhor no sentido de se livrar de um incômodo

( ) Sente que perdeu algo importante

( )Outros.

7. RELACIONAMENTO SEXUAL

Como se sentia antes da cirurgia em relação ao ato sexual

( )Ansiosa

( )Motivada

( ) Indiferente

( ) Temerosa

( )Outros.

Como se sente agora em relação ao ato sexual
( )Ansiosa
( )Motivada
( ) Indiferente
( ) Temerosa
( )Outros.

8. EM RELAÇÃO AO PRAZER NA RELAÇÃO SEXUAL

Como era antes da cirurgia

( ) Excelente

( )Bom

( )Médio

( )Não sentia prazer

( )Outros

Como é atualmente

( ) Excelente

( )Bom

( )Médio

( )Não sente prazer

( )Outros

9. NO RELACIONAMENTO COM O

\section{PARCEIRO}

Como se sentia antes da cirurgia
( ) Muito bem
( )Bem
( ) Indiferente
( ) Mal
( )Outros

Como se sente hoje

( )Muito bem

( )Bem

( ) Indiferente

( ) Mal

( )Outros. 